\title{
Research on Integrated Teaching of Computer Application Technology Image Processing Course in the New Period
}

\section{Xu Song}

School of Computer and Information Engineering, Anyang Normal University, Anyang, Henan, 455000, China

This work was financially supported by the Science and Technology Project in Henan province of China under Grant 202102110115

Abstract: In the process of computer teaching, image processing is a very important part. This course has extremely high requirements for students' professional skills. It is difficult to fundamentally improve students' abilities using traditional teaching methods. Therefore, this article focuses on the integration of art image processing courses. Exploring the model of teaching, seeking breakthroughs in the education process, and promoting the improvement of teaching quality.

Keywords: Computer Application Technology; Image Processing Course; Integrated Teaching

The computer major has been favored by many students for a long time, but under the traditional teaching mode, it is difficult to achieve the proper integration of computer theory teaching and practical teaching. The phenomenon of disconnection between the two occurs, which is important for the knowledge and skills learning of the students of the major. A lot of restrictions have arisen. In order to solve this problem, an integrated teaching model of image processing is adopted to integrate theory and practice to improve students' computer professional ability.

\section{Integrated teaching model}

The so-called integrated teaching model refers to the sorting and integration of teaching links, taking students' theoretical training and practical ability training as a whole, and making independent teaching plans and syllabuses for this, so as to cultivate students' professional ability. Goals, implement each teaching link to ensure the realization of teaching goals.

\section{Improve teachers' ability}

The training of dual-qualified teachers is imminent. For this type of teacher training, we should not just stop at the level of certificates, but really realize the implementation of innovative comprehensive capabilities and seek appropriate opportunities to allow teachers to be trained in front-line jobs. And exercise, truly participate in business practice, accumulate rich experience for teaching work, without real experience, can truly deliver valuable information to students in the classroom, and build a bridge between students and careers.

For example, teachers of image processing courses can practice in advertising companies and design work. Based on the needs of their jobs, they can explore the practical skills of image processing. Based on this, they can adjust the teaching direction in the classroom to ensure that practical skills are in The proportion of the curriculum should play the leading role of teachers in the classroom and integrate the classic cases involved in the enterprise into the teaching, so that students can realize the needs and forms of the current market, and truly meet the needs of society.

\section{Transform textbook knowledge}

Copyright $\odot 2020$ Xu Song

doi: $10.18282 /$ le.v9i7.1517

This is an open-access article distributed under the terms of the Creative Commons Attribution Non-Commercial License

(http://creativecommons.org/licenses/by-nc/4.0/), which permits unrestricted non-commercial use, distribution, and reproduction in any medium, provided the original work is properly cited. 
The textbook knowledge can be reformed and processed appropriately in accordance with the classroom needs. The separation of theory and practice has always been a drawback of traditional textbook knowledge. In many cases, if a one-to-one correspondence between theory and practice can be formed, it is actually beneficial to the development of students In order to achieve this kind of teaching purpose, teachers can modify the textbook knowledge. For some practical courses, they can integrate theoretical knowledge into them, achieve the effect of applying what they have learned, and improve the quality of students' learning. In addition, textbooks are inevitable. There will be some missing parts, especially the lack of practical parts. Teachers can use the Internet to search for relevant materials to supplement this part of the content.

\section{Reasonable proportion of courses}

Although the course has the characteristics of high practicality, the practical operation should be based on the explanation. If too much emphasis is placed on the practical operation and the explanation process is ignored, the students will be full of blindness and uncertainty in the practical operation. Inability to fully understand classroom knowledge. Therefore, teachers should pay attention to the design of time ratio when designing classroom teaching. In the 90-minute classroom teaching, reasonably arrange the time ratio of lectures, demonstrations, and practical operations on the computer. In the teaching stage, teachers should summarize the key points and difficulties of knowledge based on the content of the computer practice, and conduct thorough explanations and analysis of relevant knowledge points. At this stage, teachers are the leaders in teaching and need to fully ignite the students' passion for learning, Cultivate students' creative thinking. In the subsequent demonstration stage, teachers should conduct standardized demonstrations on the operational difficulties of computer practice, and combine the demonstration to raise questions to increase students' interest in computer practice. In the final stage of computer-based practice, teachers should change from a leader to a guide, give students sufficient time and space for autonomous operation, conduct differentiated guidance to students, summarize students' common problems, and launch in-depth explanations.

\section{Cleverly set up classroom links}

The biggest feature of the integrated teaching model is that the theoretical and practical aspects of the curriculum are fully integrated. On this basis, if you want to optimize the classroom effect, teachers can cleverly design classroom links to create a harmonious and active In addition to the classroom atmosphere, it helps students form professional professionalism, including:

\subsection{Create a situational start task}

In the initial stage of classroom teaching, teachers can create task scenarios in the form of task release, bring the classroom into the actual situation, analogize the classroom to an enterprise, and analogize the teaching tasks of graphics and image processing courses to orders, and according to the difficulty of the task Determine the remuneration of the “order" so as to fully stimulate the students' creative desire.

\subsection{Assignment of classroom groups}

In classroom teaching, students' writing skills can be improved through group cooperation. Teachers can issue learning tasks for students. Classroom learning groups should be allocated according to their difficulty. Ministers and leading cadres should be set up in the groups, who are responsible for the division of tasks Process control and time control. The selection of group leader should adopt a rotation system to ensure that each student's leadership ability can be exercised.

\subsection{Display of works results}

The work is designed according to the task in the unit of group. After the work is completed, each group needs to display the work results, and a speaker will explain it. In this way, it can not only improve students' language expression ability, but also summarize, evaluate and live in classroom teaching. While improving students' self-confidence and collective sense of honor, it also deepens students' understanding of classroom knowledge. 


\section{Concluding remarks}

In the new era, computer application technology image processing courses should achieve integrated development, fully integrating theory and practice in teaching, and this teaching mode is more popular with students, can achieve more teaching effects and improve the quality of talents .

\section{References}

1. Zhang Wenqian. An analysis of the integrated teaching mode of theory and practice in the course of graphics and image processing[J]. Computer and Network, 2020, 46(07): 41.

2. Li Chao, Luo Kai. Design practice and exploration of integrated teaching based on the flipped classroom "Photoshop image processing" course[J]. Invention and Innovation (Vocational Education), 2020(01): 60-61.

3. Zhang Xiongmei. Teaching Research on Photoshop Image Processing Integration Course [J]. Knowledge Economy, 2019(33): 156+158. 